\title{
British Universities Siberian Studies Seminar Annals and an Appeal
}

\begin{abstract}
ALAN WOOD
Older readers of Sibirica will recall (though more recent subscribers may not know) that this journal had its origins as a newsletter and report of the proceedings and papers delivered at the early conferences of the British Universities Siberian Studies Seminar (BUSSS). In September 1981, at my invitation, a dozen or so English and Scottish academics assembled for a weekend meeting at Lancaster University, UK, to present informal papers and discuss our mutual-but as yet uncoordinated-interest in Siberia, the Russian North, and Far East. (Small beginnings, but remember that there were only twelve apostles, and a mere nine delegates at the first meeting of the Russian Social Democratic Labor Party - the future CPSU-in Minsk in 1898. There was even a brief report of our meeting in the British newspaper, The Daily Mail, under the headline "No Salt Mines in Siberia!") Among the participants was the eminent Arctic geographer, the late Dr. Terence Armstrong of the Scott Polar Research Institute at Cambridge University, who offered to host a second meeting of the group at his own institution. This duly took place in April 1983, and was attended by 26 scholars, not only from Britain, but also from France, Germany, Japan, and the United States. Four papers were read, including one by Violet Connelly, the eighty-two-year-old doyenne of modern Siberian studies in the West. ${ }^{1}$ The papers were subsequently published in samizdat format by the now defunct Department of Russian and Soviet Studies at Lancaster University, and it is that pamphlet that may be properly regarded as the very first issue of Sibirica.

A third conference was held, again in Cambridge, in September 1984, and the fourth at the School of Slavonic and East European Studies (SSEES), University of London, in April 1986, jointly sponsored by the British Council, the British Academy, the GB-USSR Association, and the Ford and Nuffield Foundations. There were over 50 partici-
\end{abstract}


pants at this gathering with scholars from eight different countries including China, Japan, and Poland. Three scheduled speakers from the Soviet Union were unable to attend, but two of them - the influential sociologist Academician Tatyana Zaslavskaya from Novosibirsk and the Moscow ethnographer Dr. Sergei Savoskul-sent in their papers, which were eventually published, along with selected contributions to the conference in The Development of Siberia: People and Resources (Wood and French 1989). Another interdisciplinary anthology had appeared earlier, with all the chapters written by members of BUSSS (Wood 1987).

The next two meetings of BUSSS took place at the University of Glasgow in April 1988 and September 1989. The report of the 1988 conference published in Sibirica IV contained a list of all the then subscribing members of BUSSS, together with an indication of their research interests. There were 54 registered scholars from the UK, and 50 from 12 other countries. The 1989 gathering was distinguished by the first ever personal participation of three leading scholars from the USSRAcademician A. G. Granberg, Professor L. M. Goryushkin, ${ }^{2}$ and Dr. V. I. Lysenko, all of the Siberian Branch of the USSR Academy of Sciences at Akademgorodok. This was somewhat of a breakthrough conference as not only were the three Siberian scholars (two economists, one historian) deeply impressed by the work of BUSSS, but Academician Granberg formally proposed that the next conference should take place in Siberia itself.

Originally intended to be held at a winter sports resort in the Gornyi Altai, the venue was later shifted to Kemerovo in the Kuzbass to coincide with an international trade exhibition there. The fact that BUSSS was now sufficiently recognized to be invited to deliberate in Siberia itself was very gratifying, and a mark of the esteem in which the Seminar's activities were held beyond the Urals. Two years later, in November 1993, London University again played host to a conference jointly sponsored by SSEES and International Survival-an organization devoted to the plight of threatened indigenous tribal peoples and cultures around the world. Most of the papers were later published in a special edition of Sibirica. Thereafter, between 1995 and 2002, for a variety of organizational, financial, and personal reasons, there was something of a hiatus in BUSSS's activities. No conferences were held, and the then publisher of Sibirica went out of business. Activities resumed when in September 2002 historian and bibliographer Dr. David Collins organized what was to be the ninth conference of BUSSS at his home University of Leeds, attended by scholars from the UK, the 
United States, Russia, Canada, and Germany. At the final session, the notable American historical geographer Professor Victor Mote's offer to hold the next conference at the University of Houston, Texas was enthusiastically accepted. Also in 2002, a new publisher was found for Sibirica, and six issues appeared over the next three years under the joint editorship of me and Dr. Cathleen Brennan of Aberdeen University. The Houston conference turned out to be a huge success. In addition to many international scholars, the conference was also attended by members of Houston's local government and business community. On the last day of the conference, one of our eminent Russian colleagues, Academician Petr Baklanov, director of the Pacific Institute of Geography, Far Eastern Division of the Russian Academy of Sciences, won the vote for the next conference to be held, in 2006, in Vladivostok. That event, the eleventh meeting of the Seminar, also turned out to be a huge academic and social success, attended by about 50 specialists on Siberia and the Russian Far East, and marked the twenty-fifth anniversary of BUSSS's first meeting. In his opening address, Academician Baklanov expressed praise as well as puzzlement over the fact that the Seminar, now an international network, had had its origins not in Siberia but in Britain. A full, detailed report of the conference proceedings compiled by Joseph Long, University of Aberdeen, appeared in Sibirica in 2007.

Since then BUSSS once more hit the doldrums. As minuted by Joseph Long, during the final, plenary session of the Vladivostok meeting, a leading Moscow professor offered to host the next conference at Moscow State University in 2008/9. Sadly, nothing ever came of that offer. The professor informed me at a private meeting in London in 2008 that he lacked both the time and the financial support. This is where the annals part of this guest editorial finishes and where the appeal begins. Since taking retirement from my post at Lancaster University in 2005 I personally - though still active in research and publication-no longer have the institutional base, financial resources, or secretarial/administrative support to revive the activities of BUSSS and organize a conference myself. It would be a shame if the tradition established over the past quarter-century were to be permanently and irretrievably lost. All the previous conferences were not only useful and enjoyable occasions, but also established important links between and among fellow scholars in many different countries, and have resulted in fruitful scientific cooperation and a range of academic publications, including Sibirica itself. This unique journal continues to thrive, thanks to the energetic work of its editors and associate editors, though BUSSS, in 
which it had its genesis, remains in a state of suspended animation. Scholars will no doubt continue their awareness of each other's work through Sibirica's pages and other channels of academic communication. I appeal to anyone-individual or institution - who might be willing and able to pick up the baton, run and resuscitate the relay of earlier meetings of the British Universities Siberian Studies Seminar. I would, of course be happy to cooperate in any planning, and I am sure that the papers of such a conference, should it take place, will find a welcome home for publication in a dedicated future issue of Sibirica. If anyone has any ideas, suggestions, or proposals, please contact me at drawood@tiscali.co.uk.

\section{Notes}

1. See her obituary in Sibirica, April 1988, p. 4.

2. See his obituary in Sibirica, April 2002, pp. 8-11.

\section{References}

Long, Joesph. 2007. "Eleventh British Universities Siberian Studies Seminar: 11-15 September 2006, Vladivostok. Sibirica 6(2): 120-124, doi: 10.3167/ sib.2007.060205

Wood, Alan, ed. 1987. Siberia: Problems and Prospects for Regional Development. London, Sydney, and New York: Croom Helm.

Wood, Alan, and R. A. French, eds. 1989. The Development of Siberia: People and Resources. London: Macmillan. 